seen, a small hole had been made in the neck of the ampoule, the contents abstracted and replaced by water, and the inert and contaminated phial carefully put back in the rack, with the hole at the back, where it wa virtually invisible. Fortunately, an astute staff nurse noticed this, and Methedrine has now been withdrawn from the racks.

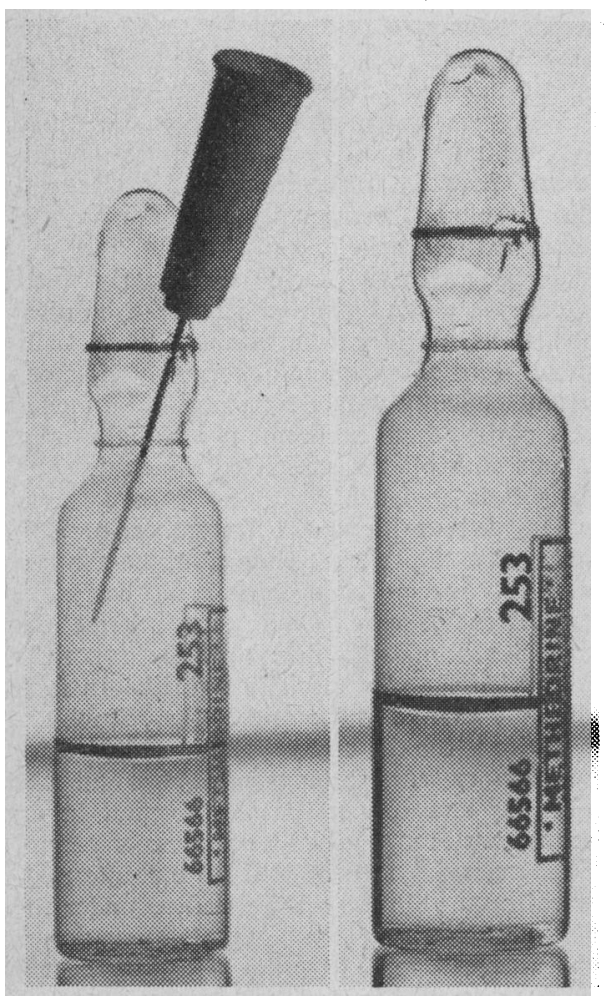

Although the enlargements make the holes appear obvious, I can assure you that in fact they were incredibly inconspicuous. It was most fortunate that no use was made of these drugs on any patient with congenital or rheumatic heart disease.-I am, etc.,

Department of Anaesthetics,
Princess Margaret Hospital,

R. B. Ror.

$$
\text { Swindon. }
$$

\section{Screening for Phenylketonuria}

SIR,-At a time when it is widely appreciated that a change must be made from the Phenistix to a more reliable method, it is particulanly regrettable that official guidance from the Ministry of Health circulated on 4 October to the regional hospital boards, local authorities, and all general practitioners should carry the heading "Screening for Phenylketonuria by the Guthrie Blood Test Method " and by every emphasis imply that this is the method of choice, and that the recommendation is based on the Report of the Medical Research Council Working Party on Phenylketonuria (5 October, p. 7). The Ministry letter, referring to the Report, says, "The evidence available at present indicates that this test [the Guthrie on blood] is least likely to fail to detect phenylketonuria in an affected newborn infant. ..." The letter fails to say that the 1965 Working Party was concerned with the appraisal of four tests and only four tests-namely, the Phenistix test, Guthrie test on blood, Guthrie test on urine, and the paper chromatography of 0 hydroxy-phenylacetic acid in urine, of which they considered the Guthrie test on blood the most satisfactory.

In point of fact the Working Party comments that the paper chromatographic technique is simply and cheaply performed in large numbers, and advocates the continued use, and further study, of alternative screening tests, but they did not themselves assess the plasma chromatographic technique ${ }^{1}$ as used by Komrower et al. in Lancashire ${ }^{2}$ at a time when the Medical Research Council study was already under way, nor did they consider the relative merits of screening procedures for inborn errors of metabolism other than phenylketonuria, though they comment that the chromatographic procedures "have the merit" of detecting more than one disease.

Experience has shown that plasma chromatography is simple, cheap, and reliable. Heparinized capillary blood samples, of which $0.01 \mathrm{ml}$. is used, are as easily collected, dispatched to the laboratory, and identified as are blood-impregnated discs for Guthrie. In practice, the quantitative evaluation of zones of growth in the Guthrie test is not always easy, no permanent record is available, borderline positive tests might be missed by junior staff suffering the boredom of repetitive work, and the rate of referral for full chemical investigation might be unnecessarily high. Preliminary screening should not be done by technicians in a bacteriology laboratory when all subsequent work must revert to a more relevant department. Indeed, if screening is to be confined to phenylketonuria then automated fluorimetry would be preferable.

When the choice plainly lies between two simple and cheap tests (such as the Guthrie and the Scriver)-one of which detects only phenylketonuria and the other phenylketonuria plus other aminoacidopathies-what possible justification can there be for choosing the limited test ? Some of the other aminoacidopathies lead to mental and physical disease whose treatment, in the interests of both patient and community, is as desirable as that of phenylketonuria. The fact that treatment of some of these conditions is at present less well established than that of phenylketonuria, or even as yet non-existent, is merely a challenge to identify the conditions and learn more of their nature, as indeed was the situation with phenylketonuria itself not so long ago.-I am, etc.,

Lewisham Group Laboratory,

\section{MARY MCMillaN.} London S.E.13.

\section{REFERENCES} 1 Komrower, G. M., Fowler, B., Griffiths, M. J., 1968, 61, 294.

Scriver, C. R., Davies, E., and Cullen, A. M.,
Lancet, 1964, 2, 230.

\section{Radiocontrol for General Practitioners}

SIR,-Radiocontrol of the domiciliary midwives in Lincoln started in December 1966. Each midwife has a small receiver and transmitter which easily fit into uniform pockets and together weigh $18 \mathrm{oz}$. (510 g.). Són after this move it became obvious that general practitioners also could use this equipment to great advantage. As Lincoln employs only 10 domiciliary midwives, and the total number of general practitioners is approximately 45 , it was felt that a number of doctors would be able to use the system without overloading the control station. Several expressed an interest and borrowed the equipment for trial purposes. Each general practitioner who tried out the equipment has subsequently decided to purchase his own set.

The scheme in Lincoln is that the general practitioners purchase their own pocket receiver and transmitter and have the use of the main transmitter equipment and control service of the City Ambulance Service-the ambulance station control room being manned day and night. The Lincoln City Council have agreed to this arrangement and make a nominal charge for the service provided. The advantages for both doctors and patients are manifold. A general practitioner is expected to be available at short notice to deal with emergencies. When he is visiting the homes of his patients, it is virtually impossible to contact him. With radiocontrol any messages requesting the doctor to visit can be transmitted to him, if necessary, as soon as they are received and time in travelling can be reduced considerably. If a general practitioner wishes to call an ambulance, order oxygen for a patient, contact the hospital, etc., he can do this by radio and does not have to leave the patient or go to the nearest telephone. The use of radiocontrol by general practitioners in and around Lincoln has gradually expanded over the past two years, and approximately half of them now use the equipment. All are most enthusiastic about the help it has been to them and also to their patients.

Several local authorities have now arranged radiocontrol for their midwives, but I am not aware of any, apart from Lincoln, which have allowed general practitioners to take part in the scheme. This is a splendid example of co-operation between general practitioners and the health department. Experience indicates that a suitable "module" is 100,000 population with about 55 general practitioners and 10 midwives. With this number, messages at busy times would not be so frequent as to lead to confusion.

The main point of my letter is to draw attention to the fact that local health authorities in many areas are organizing radiocontrol for their staff, and now is the time to organize this on a rational basis and cater for the needs of general practitioners as well. In some large cities, control has been arranged using five or six transmission stations of the same radio frequency and catering for 50 to 100 staff. Clearly, general practitioners will not now be able to join in such schemes, as the total number of participants would be excessive. I feel the time is appropriate for a working party to be appointed to consider the whole problem of communications both inside and outside hospitals. If the Ministry of Health and Social Security feels that this is not necessary, possibly the Royal College of General Practitioners could take the initiative and inquire into and report on communications outside the hospitals. The opportunity has already been lost in some areas and further delay is inexcusable.-I am, etc.,

R. D. HAIGH.

City Health Department, Lincoln. 